\title{
ETIMOLOGÍA DE LA VIVIENDA ANDINA Y SUS IMPLICACIONES EN LA ETNOHISTORIA
}

\author{
ERIK CAJAVILCA VERAMENDI ${ }^{1}$ \\ UNIVERSIDAD NACIONAL MAYOR DE SAN MARCOS, PERU
}

\begin{abstract}
RESUMEN: Las palabras que denotan la vivienda se vinculan etimológicamente con el tipo de material del que está hecha o con la apariencia fisica de la morada; no obstante, el material debe ser compatible con el hábitat. Con esta base, se analizó los nombres de la vivienda en tres lenguas andinas (quechua, aimara y chipaya) para intentar trazar un panorama respecto a la historia y tecnología de sus antepasados en tiempos precolombinos. Se encontró que los nombres de la vivienda andina, wasi, uta y qhuya, están relacionados al tipo de material con el que se hacian los techos. Asimismo, en el caso del quechua wasi y del aimara uta, su carencia de datos polisémicos que corroboren un origen intralingüistico indicaría una profunda antigüedad de los términos, por lo menos desde antes de que los troncos quechua y aimara surgieran. He propuesto que ellos procederían de una estirpe amazónica, en vista de que evocan elementos vegetales que solo se encuentran en la selva: los árboles o palmeras de hojas anchas.
\end{abstract}

Palabras clave: Casa; Etimología; Etnohistoria; Quechua; Qimara.

\begin{abstract}
The words that denote the dwelling are linked etymologically with the type of material from which it is made or with the physical appearance of the dwelling; moreover, the material must be compatible with the habitat. With this base, the names of the dwelling were analyzed in three Andean languages (Quechua, Aymara and Chipaya) in order to draw a panorama with respect to the history and technology of their ancestors in pre-Columbian times. It was found that the names of the Andean dwelling, wasi, uta and qhuya, are related to the type of material with which the roofs were made. Likewise, in the case of Quechua wasi and Aymara uta, their lack of polysemic data corroborating an intralinguistic origin would indicate a deep antiquity of the terms, at least since before the Quechua and Aymara stocks emerged. I have proposed that they would come from an Amazonian line, since they evoke vegetal elements that are only found in the jungle: the trees or palms with broad leaves.
\end{abstract}

Keywords: House; Etymology; Ethnohistory; Quechua; Aymara.

\footnotetext{
${ }^{1}$ Lingüísta y profesor de Lengua Castellana (Univerisdad Nacional Mayor de San Marcos, Perú). E-mail: 12030207@unmsm.edu.pe
} 


\section{Introducción}

El estudio de la antigua vivienda andina es un objeto ampliamente abordado por la arqueología. Dicho estudio está mediado por diversos objetivos que subyacen la práctica arqueológica para la interpretación de los restos materiales; asimismo, la arqueología muchas veces recurre a la literatura etnográfica e histórica como punto de apoyo. Alrededor de estos objetivos giran otros intereses de corte más sociológico como el de Nash (2009) quien promueve nuevos enfoques interpretativos de los espacios familiares andinos en oposición a los modelos materialistas de la construcción utilizada como refugio. Muñoz (2012) por otro lado, aborda un aspecto antropológico de la vivienda relacionado a la tecnología y a la concepción nativa del paso del tiempo. En la sección 3, informaremos un poco más sobre el aspecto arqueológico y material de la vivienda andina. En consecuencia, está de más decir que es un área estimulante para la investigación histórica de los Andes.

Ahora bien, la lingüística es otra de las disciplinas que asiste a la investigación arqueológica e histórica en general y que, en los últimos años, ha habido avances notables en el estudio de los topónimos que ofrece nuevas interpretaciones de los desplazamientos iniciales de focos culturales ancestrales. Por otro lado, la palabra misma puede ser empleada como objeto de estudio para descubrir datos que no se ven a simple vista, datos que están conectados a un sistema de significaciones que muchas veces compromete a todo un espacio macrocultural. La dinámica de la palabra compete, entre otros, relación de cognados, préstamos, cambio de significado, relación genética y relación areal, dominios que hacen uso del método comparativo y el análisis etimológico ${ }^{2}$. Dicho esto, casi no existen investigaciones que involucre la lingüística en el estudio de la vivienda andina, específicamente nos referimos a los términos quechua y aimara empleados para designar el objeto físico: wasi y uta. Ciertamente ocurre un problema cuando intentamos rastrear el origen de estos términos dentro de los límites de la lengua ya que no encontramos respuestas significativas, lo que nos lleva a enfocar el problema desde una perspectiva interlingüística. Se comprende entonces porque apuntamos a una perspectiva interlingüística o al método comparativo. De hecho, por lo general, en trabajos lexicográficos locales, se aborda la transferencia desde el quechua a lengua receptora, debido a la cantidad de préstamos que se llevaron a cabo en una época cuando el quechua tenía poder y, posteriormente, cuando los misioneros europeos la utilizaron como lengua vehicular; sin embargo, no son muy comunes los estudios sobre las palabras importadas hacia el quechua y el aimara desde otras lenguas nativas, especialmente de la Amazonía. En efecto, existirían palabras que se rastrean desde los tiempos preincaicos, en donde las lenguas

\footnotetext{
${ }^{2}$ Algunos trabajos de tendencia etimológica son los de Cerrón-Palomino, quien analiza ciertos topónimos andinos, así como el etnónimo quechua. En un ámbito más abstracto, el de teónimos, están los trabajos de, por ejemplo, Itier para Viracocha (2013); Rojas-Berscia y Ghavami-Dicker (2015) para Kanpunama'.
} 
antecesoras del quechua y el aimara eran habladas por pequeñas tribus que recibían el influjo constante de otros pueblos nativos.

En suma, el método comparativo en etimología apunta más a abrir nuevas rutas de enlace que involucren a los actores etnolingüísticos, originalmente sin relación genética, que a descubrir un significado exacto de la palabra ancestral. Así, el objetivo de este artículo es proponer alguna etimología para los nombres de la vivienda en las lenguas andinas quechua, aimara y chipaya y posteriormente hacer inferencias de corte etnohistórico. Se pretende así seguir con la línea de lingüistas dedicados al estudio etimológico y aportar con la etnohistoria de los antepasados de los pueblos andinos. En la sección que sigue, haremos primero un breve repaso de los recientes estudios sobre la sugestiva relación entre los Andes y la Amazonía para luego concentrar nuestra atención en los asuntos lingüísticos.

\section{Una relación andino-amazónica de larga data}

Nuestro estudio está motivado por el interés creciente de modelos etnohistóricos y arqueológicos que sugieren una intensa relación andinoamazónica en tiempos preincaicos. Ahora con una propuesta lingüística, aspiramos a fortalecer estos argumentos. Específicamente nos referimos a la relación entre los pueblos andinos de lenguas quechuas y aimaras, lenguas sin vínculo genético alguno con lenguas amazónicas. No obstante, sin relación genética no significa «sin relación» alguna, porque de hecho la hay, esta puede ser a través de préstamos lingüísticos, influjo cultural o religioso. Nos sumamos, así, a la línea «antiesencialista» de la Amazonía, para tomar el término de Hornborg y Hill (2011: 1), respecto a una visión de las culturas transversales influyéndose entre sí y no solo simples encuentros comerciales esporádicos.

Uno de los trabajos más sugerentes es el de Hornborg y Eriksen $(2011,139)$ donde explican la importancia de los grupos arawak subandinos como puente cultural y económico entre los andinos y los pano de las tierras bajas orientales hace 2000 años más o menos. Otro trabajo interesante, en sintonía con el anterior, es el de Wilkinson (2018) quien plantea la emergencia de estados imperiales en los Andes peruanos - Wari e Inca - impulsado por las relaciones económicas entre andinos y amazónicos, e intensificado en el Horizonte Medio (550-900 d. C.) con la importación masiva de plumas de aves amazónicas. Con frecuencia, cuando se habla de una red comercial andino-amazónica de larga distancia, los artículos sui géneris son los venenos amazónicos y las plantas narcóticas (KEOKE; PORTERFIELD, 2005, 22). Este tipo de comercio habría perdurado miles de años, mientras que el comercio de plumas recién habría alcanzado gran extensión con el advenimiento del Horizonte Medio (550-900 d. C.) donde se dio la emergencia del estado andino a partir de una red integrada amazónica y el comercio masivo de bienes amazónicos, siendo los arawak subandinos los intermediarios (WILKINSON, 2018, 1366; HORNBORG; ERIKSEN, 2011, 135, 140). 
Tenga en cuenta que antes de la división de los protoquechuas y protoaimaras, sus respectivos ancestros habitaban algún lugar de la sierra central y costa central del Perú, respectivamente (CERRÓNPALOMINO, 2010). Adelaar (2010) incluso propone que los preprotoquechua habrían llegado a la sierra central peruana a finales del Horizonte Temprano (200 a. C.) en un segundo momento, posterior a la llegada de los pre-protoaimara. Por lo tanto, muy probablemente, ellos habrían estado dentro de la esfera de interacción planteada por los trabajos mencionados.

Otros artículos recomendados son el de Morales (2001) respecto a la emergencia de los centros formativos andinos y a la iconografía compartida con los amazónicos; y Smith (2011), ampliado posteriormente por Vargas (2016), respecto a la presencia de grupos arawak en los Andes y en la costa central del Perú en tiempos prehispánicos.

\section{Aspecto etimológico general de los términos que expresan «casa»}

Una ventaja de analizar etimológicamente el término en cuestión es que refiere a algo concreto y que en principio debería estar estrechamente vinculado al tipo de recurso material que abunda en un espacio determinado, o en todo caso, relacionado a la forma de la construcción. Otra característica resaltante es que, a pesar de la modernidad, se resiste a ser reemplazado por tecnicismos modernos, más bien parece que la mayoría de lenguas retienen el ítem lexical heredado. Observe, por ejemplo, que los términos house y casa, del inglés y castellano respectivamente, son palabras que no pueden ser fácilmente rastreadas por el estudio etimológico, lo que evidencia su profunda antigüedad. Respecto al castellano, es más probable que casa ${ }^{3}$ no haya surgido en la misma rama itálica, sino sea, más bien, un préstamo de alguna lengua no itálica. Se especula dos raíces, una verbal dialectal (itálica) *kat- 'trenzar' y otra nominal indoeuropea *ket- o *kot- que señala un espacio cercado o establo (DE VAAN, 2008, 96).

¿Qué implica el hecho de que ciertas palabras son susceptibles de transmisión más allá de las barreras culturales? Ciertamente, la tecnología de la construcción de la vivienda ha sido mejorada imitando las técnicas eficientes entre pueblos distintos, de este modo, la vivienda llegó a evolucionar. Por lo tanto, cada vez que un grupo quiera imitar o usar la tecnología de otros, lo más fácil es prestarse los códigos ya existentes para identificar el producto. En este caso se dice que una cultura es susceptible de admirar o imitar los bienes y productos innovadores de otra cultura foránea y, además, reteniendo el vocablo que refiere a aquel bien o producto. Esta es la principal motivación de los préstamos lexicales; ejemplos modernos son software, facebook, pizza, champaña, etc. De otro modo, si la lengua receptora prefiere aludir al significado literal, entonces creará calcos. Muchos términos actuales de lenguas

\footnotetext{
${ }^{3}$ El italiano y el español casa y el rumano casă se derivan del nombre latino de una vivienda rústica casa 'cabaña, choza' (BUCK, 1988, 459). La vivienda de la élite se denomina domus en latín.
} 
europeas se rastrean hasta las palabras que utilizaron las primeras civilizaciones del continente euroasiático; esto implica que si separamos aquellas palabras que pertenecen al mismo tronco lingüístico, el resto de palabras confirmará una relación interétnica. Otra cuestión es que los términos traídos de afuera van a sumarse al inventario lexical como variedad; esto es, si ya se tiene un término para casa, con todas las características étnicas propias, un nuevo tipo de casa tendrá que ser nombrado de otra forma. Aunque en la práctica, los hablantes pueden, con el tiempo, nivelar semánticamente los conceptos (generación de sinónimos), intercambiar los sentidos o arcaizar una innovación léxica.

Haciendo una revisión general a la obra lexicográfica de Buck (1988), los términos para casa generalmente se derivan de términos relacionados a la forma de la vivienda o a los materiales de construcción. Asimismo, puede derivarse también de verbos como construir, cubrir, permanecer, pernoctar, descansar, estar, habitar. Por ejemplo, el latín domus 'casa' vendría de una arcaica raíz indoeuropea *dem- 'construir'; el francés maison (pasando previamente por mansio) viene del latín manére 'permanecer'; luego el latín tectum 'techo, casa' y también el

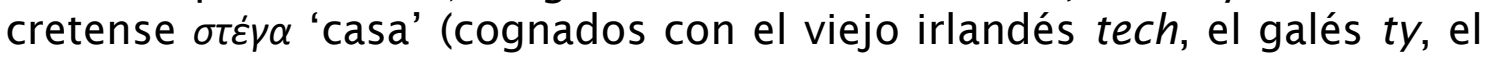
bretón ti, el griego antiguo tźyos 'techo', etc.) se derivarían de un verbo con el significado de 'cubrir', evidenciado en el verbo latín tegere 'cubrir'. Así también, en lenguas eslavas, ciertos términos como el serbocroata kuća 'casa', el búlgaro kǔšta 'casa', el eslavo eclesiástico kašta 'tienda' y el ruso kutat' 'envolver' serían derivados de un verbo indoeuropeo

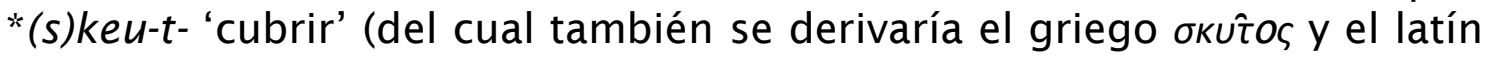
cutis 'piel, envoltura') (ibíd., 458-459).

Por otro lado, respecto a expresiones nominales, existen diversas fuentes que pueden plantearse como posibles étimos. Entre estas están los nombres de nidos ${ }^{4}$, guaridas, cuevas, etc.; el tipo de material como la piedra, la madera, la hoja, la paja, etc. Por ejemplo, en el diccionario de Buck, se insinúa que el sánscrito grha- 'casa', el gótico gards 'casa, salón' y el avéstico gərəठa 'cavern' serían cognados (ibíd., 459). Asimismo, el viejo nórdico kofi, el viejo inglés cofa 'habitación, hueco en la roca', el medio alto alemán kobe 'caseta, jaula', el antiguo griego vǘtrn 'hueco, cueva, choza' serían cognados, adscritos a la raíz indoeuropea *geu'hueco' o con 'forma redondeada'5 (vinculado también al viejo nórdico kot, al medio bajo alemán kot, kote o al viejo francés cotage 'choza') (ibíd.: 460).

Otra raíz planteada es la protoforma indoeuropea *kel- 'cubrir,

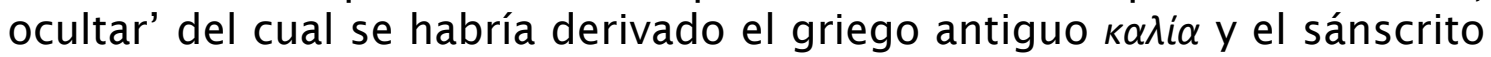
çâta- 'casa, caseta, choza'. En latín, la raíz verbal se manifiesta como

\footnotetext{
${ }^{4}$ Tenga en cuenta no apresurarse al proponer un étimo. Por ejemplo, en quechua de Santiago del Estero, wasi denota 'casa' y 'nido', aunque este último es, más bien, una extensión semántica y no el significado original (ALDERETES, 2001).

${ }^{5}$ A propósito de la motivación conceptual de la forma, el término inuit de Labrador iglo 'casa' (igloo en inglés) es cognado con aglo 'agujero de foca' (ERDMANN, 1864), el cual es un orificio en la capa hielo sobre el mar que hacen las focas para respirar. Asimismo, en el iñupiatun, encontramos el mismo patrón: iglu 'casa, dique de castor'; alluaq 'agujero en el hielo'; alluvak 'agujero de respiración de foca', tal vez derivados de la raíz iliuit- 'ahuecado' (SEILER, 2012).
} 
occulere, cetäre; en el viejo irlandés, celim y en el viejo inglés, helan 'cubrir, ocultar' (ibíd.). Asimismo, el oscuro término latino casa vendría de una antigua raíz *kat- 'cestería' del que se deriva las palabras caténa 'cadena' y cassis 'red' (haciendo alusión al estilo de construcción en forma de tejido) (ibíd.).

En principio, los originales y antiguos nombres para casa abarcan solo aquellas construcciones menores y rústicas hechas para unas pocas personas. Los nombres de grandes construcciones como palacios 0 templos que emergieron con las primeras civilizaciones, si bien algunos se derivan de los anteriores, son nombres más recientes en la historia de la palabra. En consecuencia, debemos tomar como punto de partida aquellas construcciones básicas hechas con materiales que no demande un gran esfuerzo adquirirlos, es decir, un tipo de material abundante en el entorno inmediato de un grupo social específico. Podríamos decir que se cumple un principio de dominio ecológico y es que cada pueblo está ligado a la impronta del ambiente donde vive. Como señala Saegert (1985, 288), citando a Rapoport, las viviendas son «compatibles con la ecología del área». Así, los pueblos del Ártico utilizan la nieve; ${ }^{6}$ los de las selvas, árboles; los pueblos lacustres, junco y barro; etc.

A continuación, haremos un repaso de algunos diccionarios etimológicos, señalando una probable vinculación entre la palabra que nos interesa y sus fuentes etimológicas. En adelante vamos a encontrar consistencia con lo expuesto anteriormente. Indicaré entre paréntesis los nombres de las lenguas o dialectos analizados por los autores de los diccionarios. El punto y coma separa los enunciados para cada lengua.

* En el diccionario etimológico dravídico (BURROW; EMENEAU, 1984)

Grupo lexical «casa»: il, illam 'casa' (tamil); illu 'casa, vivienda, familia' (tulu); illu 'casa, vivienda' (telugu); ella 'casa' (kolami); il 'casa' (gondi); ilu 'casa' (konda); il 'casa' (pengo); il 'casa' (manda); ị̣u 'casa, morada, cobertizo' (kui).

Probables cognados: ilai 'hoja, pétalo' (tamil); ila 'hoja' (malayalam); el 'hoja' (kota); ele, ela 'hoja' (kannada); elè, irè 'hoja' (tulu). También cognado con el árbol de algodón del cual se teje mantas o cobertores: ila (tamil), ilavam, ilavu (malayalam), elava (kannada), āla (tulu).

Grupo lexical «casa»: kuți 'casa, morada, hogar, familia' (tamil); kuți 'casa, choza, familia, esposa' (malayalam); kurjl 'cobertizo', kur! 'choza', gury 'templo' (kota); kwïs 'cobertizo', kuș 'cuarto' (toda); guḍi 'casa, templo', guḍil, guḍalu 'choza con techo de paja' (kannada); küri 'choza de ramas' (kui); kuryā 'choza de campo' (malto); kuḍ(d)ī 'choza, casa pequeña, esposa' (brahui).

\footnotetext{
${ }^{6}$ Las moradas de nieve son provisionales. Los esquimales generalmente viven en chozas de pieles y ramas o algún otro material.
} 
Probables cognados: kūrai 'techo inclinado de paja, choza pequeña' (tamil); kūra 'choza, paja' (malayalam). También cụ̄li 'escamas, piel de semilla' (malayalam); cuguli 'cáscara', cōli, sūli 'piel, corteza' (tulu).

Otros probables cognados: kuțai 'perforar, penetrar', 'algo ahuecado, cesta para comer', kuțā 'cavidad, caverna' (tamil); kudy 'fosa, mortero', kudc- 'hacer un hueco' (toda); kode 'ahuecar, excavar' (kannada), kudè, guḍè 'hueco de rata' (tulu); khodrā 'agujero de tronco' (kurux).

Grupo lexical «estancia»: ceccai es un "lugar de descanso con techo de follaje' (tamil) y cecca 'casa de hojas' (malayalam). Posible vínculo con cekil 'piel, corteza de fruta, escamas' (tamil); cegalo 'corteza de árbol' (kurux); ceglo 'cáscara de fruta' (malto).

Grupo lexical «choza», «techo»: purai 'casa, vivienda', pirai 'cobertizo' (tamil); pura 'casa de paja, choza, cuarto' (malayalam); pore 'techo de paja' (kodagu); porè, purè 'techo', pura 'casa' (tulu). Posible vínculo con purai 'catarata del ojo' (tamil); pore 'pliegue, capa, estrato' (kannada); pora 'capa, película, membrana, piel, pliegue' (telugu); poro 'capa' (konda).

* En el diccionario etimológico hebreo (KLEIN, 1987)

Grupo lexical «sombra»: tzēl 'sombra, albergue, protección'. Cognado con tlālāa (arameo); tālālāa (siríaco); zl (ugarítico); selālōt (etiope); sillu (acadiano) 'sombra'; tatlaltāa 'albergue, choza' (arameo); mzlll 'techumbre' (ugarítico); mizallah, mazallah 'paraguas, sombrilla' (árabe). Posible vínculo con tzll 'estar oscuro, oscurecer'; mtlaltāa 'techo, choza' (arameo); mizallah 'techo, choza' (árabe); mzll 'techumbre, casa' (ugarítico); masallu 'lugar de descanso' (acadiano).

* En el diccionario etimológico hamito-semítico (OREL; STOLBOVA, 1995)

Grupo lexical «construcción»: *byan- 'tienda, casa' (beréber); bnbn 'estela' ['Iosa'] (egipto); *byani(H)- 'piso superior, choza' (chádico occidental); " binVH- 'choza' (chádico central); *byaHin- 'choza' (chádico oriental). Según los autores, estas son formas nominales del verbo construir: ‘ $b V n$ - 'construir' (semítico); " $b V n$ - 'construir' (beréber); *byani $(H)$ - 'construir' (chádico oriental). No obstante, este verbo sería una extensión semántica de un significado más específico (< 'atar'): *bVn'atar' (beréber); *byan- 'atar' (chádico central); aludiendo, entonces, que las casas de los pueblos hamito-semíticos estaban hechas de algún material entretejido.

\footnotetext{
${ }^{7}$ Aquí transcribo las palabras en alfabeto latino. Para hacer la conversión véase las «reglas de transliteración» (KLEIN, 1987, XII-XIII).
} 
Grupo lexical «choza»: *but- 'casa de barro' (beréber); *but- 'choza' (chádico occidental). Estas formas recuerdan a una raíz que denota algún tipo de vasija: *batt- 'botella' (semítico); *buHat- 'botella de calabaza' (chádico occidental); *bVt- 'olla' (chádico central); *but- 'olla' (saho-afar); *bot- 'jarra grande' (cushita del este); *bat- *bot- 'calabaza' (omótico). El vínculo etimológico se establece a partir del tipo de material usado en ambos casos, el barro. En el diccionario encontramos algunas formas parecidas con dicho significado: *ba- 'lodo' (chádico central); *bas- 'barro' (cushita del sur); ‘baș- 'arena, barro' (semítico); *buc- 'tierra' (cushita del este).

Otros probables cognados: *but- 'ombligo, vientre' (beréber); *but‘vientre, estómago' (chádico occidental); *baț(t)- 'vasija' (semítico); *buț'fondo de vasija' (beréber). No obstante, «vientre» no sería el significado original de la palabra ya que existen otros términos para estómago o vientre, por ejemplo: ‘?ur- 'estómago' (chádico central); ‘?ur- 'ombligo' (chádico oriental); *?ur- 'vientre' (cushita del este bajo); *gVdVb- 'vientre' (chádico central); ‘godeb- 'vientre' (cushita del este alto).

Grupo lexical «casa»: *gudd- 'ciudad' (semítico); *gud- 'casa' (chádico central); “god- 'choza' (cushita del este alto); *god- 'lugar, corral' (cushita del este alto); *kot- 'casa' (werizoide). También *gVrur- 'recinto, pared' (beréber); ‘gur- 'lugar' (chádico occidental); ‘gur- 'recinto' (chádico central).

Probables cognados: “gūr- 'cavidad' (semítico); *gur- 'agujero' (chádico oriental); 'guta- 'calabaza' (chádico central). Otros cognados: ‘guž'órgano interno' (chádico occidental); ‘giž- *guž- 'vientre’ (chádico oriental); *guž- 'vientre' (saho-afar); *giri?- 'estómago' (semítico); *gur'estómago' (chádico oriental); ‘gurV?- 'vientre' (cushita del sur).

* En el diccionario etimológico del antiguo chino (SCHUESSLER, 2007)

Entrada lexical: kjun 'palacio, mansión'. Propuesta etimológica del autor: $k^{h}$ on-pa 'interior' (tibetano escrito); *k-yim *k-yum 'casa' (proto tibetano birmano).

Probable cognado: $k w e \eta$ 'vasija' hecha de cuerno de búfalo. Etimología: " $k r o \eta^{A}$ 'cuerno' (proto miao yao); 'k-rwan ${ }^{A}$ 'cuerno' (proto tibetano birmano).

Entrada lexical: yâp 'tapar, cubrir, techar con paja, cerrar', 'puerta de corteza'. Cognado: kai 'cubierta, tapa'. Propuesta etimológica del autor: gebs-pa 'cubrir', $k^{\text {hebs }}<$ *keps 'cubierta' (tibetano-birmano y tibetano escrito); *kapt *kap 'techar con paja, cubrir con manta' (protokiranti). 
Entrada lexical: $k^{h j ə m}$ 'manta, colcha'. Propuesta etimológica del autor: ?jəm 'cubierto, nublado', ?jəm ${ }^{c}$ 'albergar, sombra's; $k^{h} r u m \sim k^{h} y u m$ 'cubierto por plantas' (birmano escrito); grum-če 'manta gruesa' (tibetano escrito); khyim 'casa, refugio, abrigo' (tibetano escrito).

\section{La vivienda de los antiguos peruanos y sus términos para «casa»}

La tecnología de la casa familiar andina no cambió mucho durante los últimos milenios antes de la invasión europea. Es una ventaja ya que no hay muchos márgenes de modalidad para hacer suposiciones. En efecto, el estilo y la técnica constructiva de la vivienda doméstica de los amerindios precolombinos son muy parecidos al estilo y técnica del neolítico del Europa: viviendas de piedra, de adobe, de cañas entretejidas y barro, con postes de madera hundidos en el suelo en el centro o laterales, con ramas atadas en forma de cúpula, con techo de fibra tejida, con techo de paja, con cobertura de pieles, pithouse o pozo-casa, etc., siendo a veces unifamiliar o multifamiliares (SCARRE, 2013, 207-208, 212, 224, 246; PRICE; BROWN, 1985, 169, 328, 348, 432). Todas las moradas de la gente común, a excepción de los templos y casas de los soberanos, eran, desde nuestro punto vista, simples y rústicas. Se podría decir que los amerindios precolombinos todavía estaban pasando por un periodo lítico en pleno siglo XV. Si bien los europeos de la época colombina usaban los mismos materiales que los amerindios (madera, barro, piedra), su técnica de construcción era distinta.

La presencia de viviendas fabricadas en los Andes occidentales es tan antigua como la presencia de los primeros sudamericanos. Por ejemplo, en la costa chilena de Coquimbo, se han encontrado asentamientos desde 13500 a 10000 años AP (MÉNDEZ, 2015, 41-43). Los arqueólogos han descubierto que los pescadores de Paloma en el valle de Chilca (7000-4800 a. C.) construían viviendas cónicas de armazón de cañas cubiertas de pasto tejido o juncos (LAVALLÉE, 2000, 129). En Tumbes, se han encontrado restos de pequeñas viviendas elípticas de paja con poste en el centro (4700-4300 a. C.) y cazas rectangulares de zarzo y arcilla (900-500 a. C.) (MOORE, 2012, 6). A comienzos del periodo cerámico (2500 a. C.), en el valle de Valdivia, Ecuador, las viviendas eran más sólidas y grandes ya que se usaban postes grandes de madera (como columnas) y las paredes eran de tallos tejidos rellenado con tierra húmeda. A finales del precerámico comienzan a aparecer grandes estructuras sólidas como aquellas de Aspero, entre 4800 y 4600 AP, en el valle de Supe, que fueron templos de forma piramidal hechas de bloques de barro (adobe) sobre bases de piedra (LAVALLÉE, 2000, 198). En la sierra, las más antiguas grandes estructuras de piedra que se conocen hasta ahora son las de Chavín de Huantar en el alto Marañón (1000-200 a. C.), la cual contrastaba con las pequeñas viviendas de adobe de la clase baja (MANDRINI, 2013, 127).

\footnotetext{
${ }^{8}$ Véase la entrada lexical $<\bar{y}_{\overline{1}}{ }_{5}>$ para los enunciados ?jom y ?jom ${ }^{C}$.
} 
Por otro lado, las cuevas siempre han sido usadas como guarida o refugio para protegerse del sol o del frió o simplemente para esconderse de invasores o saqueadores; no obstante, son conocidos también los refugios temporales de roca en lugares donde se explotaba algún recurso natural. Por ejemplo, el caso de Pucuncho y Cuncaicha, en los Andes arequipeños, es notable por su antigüedad, cuya presencia humana data desde 12 800-11 500 AP. Rademaker et al. (2014) informan que los hombres establecieron campamentos de base en estos refugios rocosos con el fin de explotar la obsidiana y para la caza de camélidos. Estamos tomando en cuenta todos los posibles objetos naturales cuyos nombres podrían considerarse como posibles fuentes etimológicas. Ya sean permanentes o estacionales, los tipos de moradas estaban relacionados a los factores ambientales y a la disponibilidad de la materia prima del medio.

Desde el punto de vista ecológico, en el territorio peruano, se vislumbra tres áreas geográficas más o menos generales: la costa cálida y semidesértica con bajas precipitaciones; la sierra de clima frío y templado con vegetación parcial (mayormente herbazales) debido a su clima seco sobretodo en el flanco occidental de la cordillera y, finalmente, la selva lluviosa y cálida del oriente en cuyas tierras bajas abundan los árboles de hojas anchas. Siguiendo el principio del dominio ecológico (véase §2) no debería ser complicado deducir los tipos de casa en el antiguo Perú. Bernabé Cobo $(1893,163-168)$ señala precisamente los tipos de viviendas de los antiguos peruanos según estas consideraciones geográficas, observe la relación con el material utilizado: en la costa, se caracteriza por el uso del junco, ramas y quincha; en la sierra, la piedra y la paja y en la selva, la madera y las hojas. Otro material usado tanto en la costa como en la sierra es el adobe (bloques de barro). De este modo, en teoría, los pueblos andinos denominarían a la casa con palabras derivadas o vinculadas a los materiales de su entorno: la piedra y la paja. Estas casas andinas son circulares con techos en forma cónica y cuadradas con techo a dos aguas y mojinete; las paredes son de piedra (aprox. de 1,7 m de alto) empastadas con barro. Para la estructura de la vivienda cuadrada, se utiliza maderos como vigas sobre el cual se amarra la estera y encima la torta de paja de más de $80 \mathrm{~cm}$ de grosor (ibíd.: 166167). A continuación, presentamos el análisis de las palabras en las lenguas quechua, aimara y chipaya (se indica entre paréntesis las abreviaturas de los nombres de autores).

\subsection{En el quechua}

El término más usual para 'casa' es /wasi/. En los diccionarios se reporta tanto con la grafía $\langle\mathrm{w}\rangle$ como con $\langle\mathrm{h}\rangle \mathrm{y}\langle\mathrm{gu}\rangle$ : huaci $(\mathrm{HOL})$, huaçi (RU), guacin (STO), wasi (WE), huasi (TSC), huasi (ODT), huasi (MID), wasi (TOD), wasi (LAN), huasi (GR), huasi (O\&W), wasi (ALD), wayi (BL), wayi (ADE). Observe que la segunda sílaba aparece variadamente con sonidos fricativos sibilantes: alveolar /s/, predorsodental <ç, c> /s/ y alveolar ensordecida $\langle s\rangle / \mathrm{s} /$; asimismo, con una semivocal palatal /y/. De hecho, 
la forma más antigua debería ser alguno de estos sonidos sibilantes, más probablemente $/ \mathrm{s} /$, si tomamos en cuenta que la semivocal palatal $/ \mathrm{y} / \mathrm{ha}$ resultado de $/ \mathrm{s} /$ a través de un proceso gradual descrito por Torero $(2003,24,28)$.

A partir de wasi se derivan otros nombres como akahuaci 'taberna', aya huaci 'sepultura', aycha huaci 'carnicería', kapac huaci 'casa real [templo]', huatay huaci 'cárcel' (HOL). Por otro lado, es también conocido el establecimiento que brinda refugio a los viajeros: tampu o tambu. Existen también otros términos como aquel que expresa una caseta provisional hecha de ramas: chhuclla (HOL); chuclla (WE), ch'uclla (TSC), ch'ujlla (MID), chuclla (GR) 'choza'. Ahora bien, enfocándonos solo en el término wasi, este parece ser original del protoquechua y es el que se ha difundido a través de todas las variantes quechuas. No hay indicios de que wasi esté vinculado a la forma, tampoco al tipo de material frecuente - como la piedra o el barro- para la fabricación de la vivienda andina precolombina; más bien parece que está relacionado al ámbito vegetal. Si fuera el caso, habría que encontrar datos que corroboren la existencia de una raíz quechua vinculada semánticamente al ámbito de la construcción o a la vivienda en los Andes.

En primer lugar, dentro de la lengua, no se reportan términos polisémicos que nos indique un probable significado original. No obstante, */wasi/ parece estar conectado con otros términos que contienen el segmento /wa/. Este habría sido antiguamente un morfema que denotaba un tipo de hierba, fibra vegetal o incluso al verbo tejer. Por ejemplo, encontramos, en los diccionarios, el verbo ahuani 'tejer' (HOL) y el nombre ihua 'yerba' (MID). Estos conceptos son compatibles con la característica de las casas de los antiguos, en donde los techos son tejidos de paja, asimismo los horcones, las varas del techo y la estera solo se amarraban (no existía el clavo) (COBO, 1893, 167). Existe también una palabra que denota el techado o la acción de techar con un manifiesto sufijo fosilizado /-wa/, este es curahua 'barda de pared' (HOL); qhurahua 'cornisa de paredes o cercos' (MID). La barda es la torta de paja o bálago del techado, por lo tanto, el verbo bardar indica la acción de techar con este material ${ }^{9}$. El primer elemento radical, */qura $/{ }^{10}$, es el nombre de la hierba que crece como maleza, conocida también como paja o ichu que crece de forma natural. Tenemos, entonces, que qurawa es una palabra formada por composición entre un verbo y su objeto nominal: qura + awa > qurawa 'tejer la paja' o 'tejido de paja', traducción que es compatible con la definición de barda. El concepto «tejer» evoca no solo a la acción de entrelazar, sino también al material que se somete a tal acción (definitivamente el verbo fue derivado del nombre). Observe la siguiente lista extraída de diccionarios quechuas en donde se advierte la protoraíz */-(a)wa-/ en un campo semántico compartido.

\footnotetext{
${ }^{9}$ En el diccionario Sopena, barda se define así: «Conjunto de sarmientos, paja o espino, con que se cubren las tapias de los corrales y huertas» (SOPENA, 1981).

${ }^{10}$ Los cognados también se evidencian en otros troncos lingüísticos. En aimara, tenemos qura 'cizaña', 'mala hierba'; kurä kuraya 'barda de la pared' (BER). En yanesha, encontramos palabras formadas con esta raíz: corahua? $\sim$ corahuach 'especie de palmera que se usa para hacer esteras' (DUF).
} 
Espaço Ameríndio

chhahuar
chahuar
ahuani
huasca
huatani $^{11}$
quehua
guacora
ahuani
ahua
kehua
ahua
keshhua
huasca
huata
kihua
ahua
kisihua
huasca
ihua
qehua
ahuay
huatay
guewa
awan
wasca
watan
kiwa
awana
watana
waska
quiwa
awana
wasca
watana
quihua, jihua
ahuana
huasca
huatana
ahuana
aay

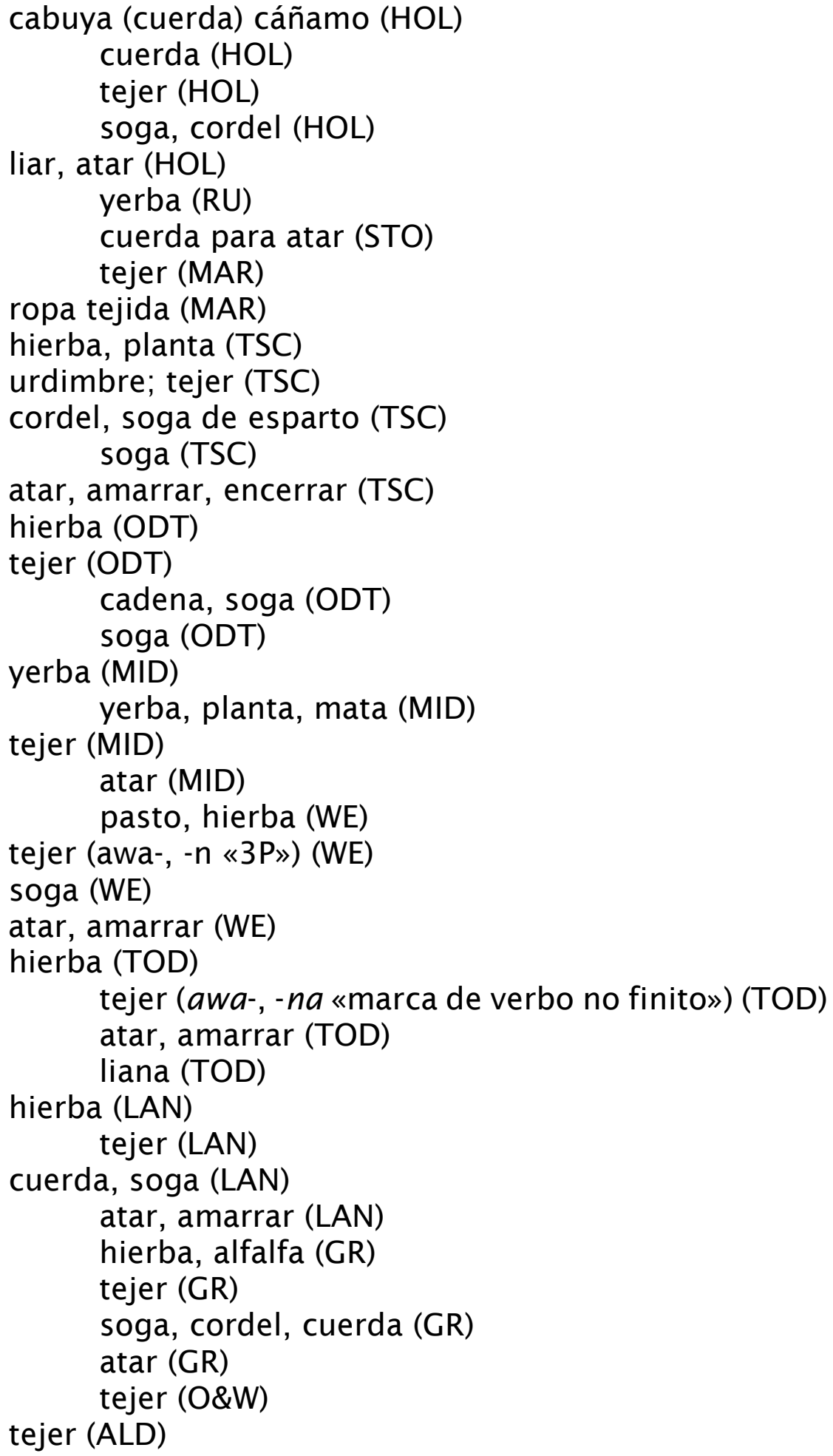

Sabemos que tradicionalmente la cuerda o la soga se hacen de fibras vegetales como las hojas, la paja, el esparto o la corteza. Así, pues, ¿sería la raíz */-(a)wa-/ una parte del término wasi denotando 'tejer' o algún tipo de fibra vegetal (p. ej. 'hierba')?

La cuestión es que los datos anteriores, de los que se extrajo la supuesta raíz */-(a)wa-/, son reportados en los dialectos quechuas,

\footnotetext{
${ }^{11}$ Segmentación: -ta verbalizador ¿?; -ni 1P sujeto, funciona como terminación verbal.
} 
mientras que */wasi/ no se registra con otro sentido en ningún dialecto quechua, ni tampoco en lengua andina conocida que no sea una ampliación semántica. Esto implicaría, por lo tanto, que el término */wasi/ sería una adopción foránea. Analicemos esta hipótesis. Justamente, en lenguas de la familia arawak, encontramos términos con bastante parecido a la palabra quechua */wasi/. Vamos a plantear la raíz */basi/ o */pasi/, la cual denota la acción de cubrir, hacer el techado y también el material principal del que se hace, es decir, la hoja; véase el Cuadro 1. Tenga en cuenta que las moradas de la selva se caracterizan por estar bien ventiladas; entre el $\mathrm{s}$. XVI-XVII, se reporta casas levantadas solo de horcones sosteniendo el techo de hojas de palmera; si hay paredes, estas son de cañas (COBO, 1893, 164; JIMÉNEZ DE LA ESPADA, 1885, Apéndice III, XCVI). Es evidente que el proceso del techado es una actividad conceptualmente sobresaliente del que puede servir para derivar nombres para casa (ya vimos los ejemplos propuestos del §2 como el caso del dravídico y del hebreo). Veamos, entonces, la siguiente lista de cognados arawak'

Cuadro 1: Cognados de la raíz */basi/ */pasi/ en lenguas arawak

\begin{tabular}{|c|c|c|}
\hline Raíz & Enunciado & Traducción \\
\hline /pašik-/ & pashicaantsi (PA) & cubrir, tapar \\
\hline */pasī-/ & pashiro & $\begin{array}{l}\text { atadijo, árbol cuya corteza se usa } \\
\text { como soga }\end{array}$ \\
\hline /aši-/ & nashitero $^{13}(\mathrm{KIN})$ & cubrir, cerrar \\
\hline /ßasi-/ & vashitagantsi (SN) & cubrir con hojas en forma de techo \\
\hline /-pasi// & opashi (SN) & hojas del techado \\
\hline /-basí-/ & ibasiqueri (SHA) & cubrir \\
\hline /-basi/ & obasi (SHA) & su hoja \\
\hline */basi/ & $\begin{array}{l}\text { pasiro, } \\
(\mathrm{SHA})\end{array}$ & $\begin{array}{l}\text { sachahuasca (planta cuya corteza } \\
\text { fibrosa sirve para amarrar el } \\
\text { armazón de las casas) }\end{array}$ \\
\hline */basi-/ & basirotsa $^{14}(\mathrm{SHA})$ & $\begin{array}{l}\text { soga (corteza fibrosa) de la planta } \\
\text { sachahuasca }\end{array}$ \\
\hline */waši-/ & washichlu $^{15}(\mathrm{NI})$ & lo techa \\
\hline */waš-/ & washre (NI) & techo de palmera \\
\hline /-wSì/ & $\begin{array}{c}\text { giwshi } \underset{(\mathrm{NI})}{\sim} \text { towshi } \\
\end{array}$ & hoja de palmera para techar \\
\hline
\end{tabular}

Así, en los pueblos arawak, se hace evidente la importancia de las hojas de los árboles (palmeras) para la construcción de las viviendas, una práctica común en los pueblos de regiones tropicales. Precisamente, el término más común para casa en las lenguas arawak occidentales se

12 En el Cuadro 1, se reportan datos de las lenguas arawak ashéninka, ashánninka, matsigenka, nomatsiguenga (conocidas como lenguas campa arawak) y piro.

${ }^{13}$ Segmentación: $n$ - 1P sujeto, -ashi- 'cubrir', - $t$ epéntesis, -e no futuro, -ro 3P objeto directo.

${ }^{14}$ Segmentación: basi- 'corteza'?, -ro marca de género fosilizado, -tsa sufijo clasificador 'fibra'.

15 No está claro si la consonante africada /č/ forma parte de la raíz verbal, /wašič-/, o es un sufijo desconocido. El último sufijo - $l u$ indica la $3 \mathrm{P}$ objeto. 
deriva de */pan/ 'hoja', p. ej., pancotsi (PA); panchi (NI), -paanu (AL) 'casa', etc.

En el Cuadro 1, observamos que el nombre puede bien funcionar como verbo con el sentido de «cubrir» o «techar». Asimismo, se reporta una forma más reducida del concepto «hoja»: -shi sufijo clasificador de hoja (PA); oshi 'hoja' (raíz -shi) ${ }^{16}$ (KIN); oshi 'su hoja' (raíz -shi) (SN); osi 'hojas, hojas de palmera para techar' (raíz -si) (SHA). Tanto la forma bisilábica como la monosilábica radical pueden funcionar también como verbo, p. ej., de la lista anterior, -basi- como nombre 'hoja' y como verbo 'cubrir'; -si- como nombre 'hoja' y como verbo 'techar'17 (SHA). En el ashéninka del Perené, -shi se ha gramaticalizado como un sufijo derivativo indicando 'objeto flexible o delgado', p. ej, novankoshi 'mi choza provisional' (MIHAS, 2010, 106). Snell, a modo de comentario, dice: «La forma -shi aparece como clasificador con varios significados como, p. ej., hoja; monte; campo poblado de árboles o plantas iguales; lugar donde están enterrados varios muertos; abundancia de plantas, mala hierba o árboles» $(2011,335)$. El morfema o raíz */-si/ de las lenguas arawak, analizado separadamente, conlleva a otras interpretaciones; no obstante, aquí lo vamos a tratar como parte inseparable de la raíz derivada. En suma, está claro lo que implica el significado de */basi/ en los datos arawak del Cuadro 1; el problema radica en cómo vincularlo etimológicamente a la palabra quechua wasi. Advierta que estas lenguas arawak son colindantes a los Andes peruanos, mientras que otras lenguas de la familia un poco más alejadas, no reportan estos cognados. Por lo tanto, ¿sería */basi/ originalmente del protoquechua con el sentido de «hoja» o «techar» y que fue luego prestado a lenguas del tronco arawak alrededor de su homeland? Si fuera así ¿por qué no existe rastros lexicales de */basi/ denotando 'hoja' ni siquiera en el quechua del siglo XVI? La única respuesta posible es que la protoforma es mucho más antigua que el periodo de sus protolenguas. Pero esto implicaría una revisión de la misma protoforma: ¿es */basi/ o */wasi/?

De hecho, hay un vocablo interesante presente en las lenguas pano, que a todas luces sería un préstamo del protoquechua: */wasi/ ${ }^{18}$. Este refiere, así como en la Amazonía, al material con el que se hacían los techos en las tierras altas. Véase los siguientes cognados pano: huasi "especie de hierba de las alturas"19 (LOR); uasin (FL); huasi (LO); huansi (NAV); huasi (STE); wasin (ZAR); basi (SH); basi (MON); baçi (AB); vazi (HY); faasi (SC) 'hierba'. Ciertamente, */wasi/ no es original del tronco pano a la luz de otros términos que ellos utilizan para denominar a la hierba en general, p. ej., nishi 'hierba enredadera', shobi 'maleza, cizaña' (LOR); xachi 'pasto' (HY); chaka 'hierba alta', nave 'maleza, hierba alta' (MON); chucu 'hierba', ro 'hierba' (SH). Ahora bien, en el quechua actual, para expresar 'hierba' o 'paja', se utiliza términos como ichhu, chhalla,

\footnotetext{
${ }^{16}$ En ciertas gramáticas, el segmento vocálico al inicio de palabra (incluso con la forma \#CV en piro), es el mismo prefijo de tercera persona $(o-\sim i$-), pero que ha sido fosilizado a la protoraíz.

${ }^{17}$ Encuéntrese la raíz en el diccionario de SHA como yosiquero 'él lo techó'. Segmentación: $i$ - prefijo 3P sujeto, -osi- 'hojas', $-k$ perfectivo, -e no futuro, -ro 3P objeto.

${ }^{18}$ Forma del protopano propuesta por Oliveira $(2014,483)$.

${ }^{19}$ De huasi se deriva precisamente huasimanan 'Gran Pajonal' (de manan 'cerro') (LOR).
} 
huaylla, ogsha, kachu, kihua, es decir, ninguno tiene la forma */wasi/. El planteamiento del préstamo del quechua al pano radica en una confusión ostensiva. Esto será explicado en el §4 sustentado con datos etnohistóricos.

\subsection{En el aimara y el chipaya}

En el aimara, el término más común para casa es uta, no obstante, también existen otros términos: anaqa 'choza temporal', qamaña 'casa de piedra', putuku 'casa de adobe en forma de pirámide trunca', uyaña 'morada' (HUA); иуи 'casa de campo' (MPF). Ahora bien, hay otro término, */čuxlla/, que manifiesta, en su etimología, el elemento típico de la región, la hierba o paja, por ejemplo: chhuxlla 'yerba' (BER); chhujlla 'pasto' (HUA); ch'ojña 'pasto' (CER). Son, pues, cognados con Ilujlla 'casa cubierta con poco ichu' (BER), ch'ujlla 'choza de paja' (HUA); cchujlla 'choza' (MPF); chuxla 'choza' (SE); chhulli 'choza' (CER). En vista de que no podemos asegurar la antigüedad precolombina del término */čulla/ debido a que no se descarta una corrupción de la palabra castellana choza o una acomodación entre el aimara chhalla 'paja' y el castellano choza, en esta sección, se intentará de averiguar el origen solo de la palabra uta 'casa', además siendo este el término más común en los dialectos aimaras.

El primer pensamiento que nos impulsa es vincular uta al significado de los materiales más representativos de la vivienda andina: la piedra y la paja. Sin embargo, tal vínculo etimológico intralingüístico es nulo. Al parecer también sería una palabra adoptada de una protocultura que no pertenecía a la ecorregión andina. Siguiendo el hilo conductor del quechua, planteo lo siguiente: la palabra uta sería de origen arawak en el que se ha fosilizado el prefijo de tercera persona a una antigua raíz */-ta-/ que denotaba 'corteza' o 'rama' (indudablemente remitía a algún elemento vegetal). Posteriormente, el sentido se extendió al concepto de «cubrir» o «techar». Este segmento es reportado actualmente, como sufijo clasificador y como raíz independiente con los significados ya antes mencionados, véase la siguiente lista en lenguas campa y en piro.

Clasificadores:

-tha clas. 'bejuco, cáscara, tallo' (PAYNE, 1980, 29)

-tall clas. 'escama, cáscara, corteza' (DUFF-TRIPP, 1997, 263)

Raíces verbales y nominales: 
Cuadro 2: Cognados de la raíz */-ta-/ en lenguas arawak

\begin{tabular}{|c|c|c|}
\hline Raíz & Enunciado & Traducción \\
\hline$/$ tha- $/$ & thataantsi ${ }^{20}(\mathrm{PA})$ & amarrar \\
\hline /-ta-/ & notataquero $^{21}(\mathrm{KIN})$ & cubrir, techar \\
\hline /-ta-/ & itaquero (SHA) & él lo tapó \\
\hline $\mid-\mathrm{ta} /$ & otataroqui (KIN) & techo \\
\hline /taki-/ & taquitsi (PA) & cáscara \\
\hline /-taki/ & otaki $^{22} \quad(\mathrm{SN})$ & su corteza, su cáscara \\
\hline /-taki/ & otaqui (SHA) & su corteza, su cáscara \\
\hline$* /-$ ta-/ & $\begin{array}{l}\text { otatoro otatocoro }{ }^{23} \\
\text { (SHA) }\end{array}$ & $\begin{array}{l}\text { su tapa, esteras que cubren } \\
\text { el techo de una casa }\end{array}$ \\
\hline /-ta/ & gita $\sim \operatorname{tota}^{24}(\mathrm{NI})$ & corteza de un árbol \\
\hline$/-\mathrm{ta} /$ & tota $(\mathrm{NI})$ & $\begin{array}{l}\text { caparazón, casco de algunos } \\
\text { animales }\end{array}$ \\
\hline
\end{tabular}

Por otro lado, en el diccionario aimara de BER, encontramos la definición de un tipo de caseta provisional que se hacía con ramaje y corteza: utachanuqaña ${ }^{25}$ 'poner una casa en el campo, armándola y

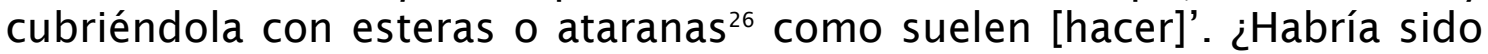
este tipo de refugio uno de los primeros que construyeron los antiguos protoaimaras? De ser así, implicaría que los protoaimaras estaban asentados en una zona cálida o templada. Este no es el único dato que sale a luz, también están los siguientes: qinchata uta 'ramada de esteras'; waylla uta 'ramada cubierta de ichu' (BER). Claramente, estos enunciados evidencian que uta denotaba una morada hecha de ramas o corteza y no una construcción hecha de piedras como aquella descrita por Cobo (véase al principio del § 4). Asimismo, otras palabras derivadas de esta hipotética raíz */-ta-/, en aimara y chipaya, incluidas en el mismo campo vegetal son thaki 'rama' (BER); tara 'arbusto medicinal' (HUA); thara 'rama' (CER).

Ahora bien, en lenguas pano abundan los datos con este segmento */-ta-/ denotando también elementos vegetales: tas'ha 'palo seco', tapan 'palos de madera amarrados', tapon 'raíz' (LOR); tara 'palo arrastrado por el río', taxa 'palizada' (HY); tada, taxa 'palizada' (MON); tara 'palo podrido', taxa 'palizada' (LO); tara 'madera de deriva' (SH); tara 'palizada' (SC); tara 'palo podrido' (AB). Para nombrar a la 'raíz' tapon (LOR, HY, LO, SC), tacha (MON, AB); al 'tallo' tako (HY), taku (MON), taui (FL); a la 'caña brava' tahua (LOR, LO, SC, FL, STE) y a la 'caña' en general taa $(\mathrm{HY})$; tava $(\mathrm{MON})$, tawa $(\mathrm{AB})$. Incluso constituye el nombre de la pona,

\footnotetext{
${ }^{20}$ Segmentación: tha- 'amarrar', -t- epéntesis, -aantsi marca verbal no finito.

${ }^{21}$ Segmentación: no-1P sujeto, -ta- 'techar', - $t$ - epéntesis, - $a k$ perfectivo, -e no fututo, -ro 3P objeto.

22 Encuéntrese en el diccionario (SN) con el prefijo de 3P sujeto. La raíz -taki es derivada de la protoraíz -ta y un antiguo sufijo clasificador de cosas duras, - $k i$ (MIHAS, 2010, 106). Actualmente, en el matsigenka, el sufijo - $k i$ funciona solo como clasificador de semillas y frutas.

${ }^{23}$ Se especula acerca de la raíz verdadera, ¿es ta- o tato-? Si fuese el primero, la segmentación sería así: o$3 \mathrm{P}$ poseedor, -ta- 'tapar', -to epéntesis, - $k$ o sufijo verbal 'en', -ro nominalizador.

${ }^{24}$ En piro (yine), los nombres inalienables se citan con el prefijo de tercera persona gi-/to-.

${ }^{25}$ Segmentación: $u t a-$ 'casa', -cha factivo, -nuqa ubicativo, - $\tilde{a} a$ marcador verbal no finito.

${ }^{26}$ Este término no se reporta en el diccionario de BER. Al parecer es sinónimo de estera o refiere a algún entramado hecho de fibras vegetales. En el quechua de ODT, encontramos atara 'cobertura'.
} 
muy utilizada para la construcción de la casa, véase los cognados: tao (LOR), taoo (HY), tau (MON), tao (LO), to (SH), tao (SC), tau (STE).

En suma, hay una importante tendencia a suponer que uta ha sido derivado de una antigua raíz nominal amazónica, */ta/. En las mismas lenguas pano, esta raíz ha producido sentidos vinculados al concepto de sombra y refugio. Los cognados con el sentido de "sombra» son ota (LOR); hota (HY); hota (LO); hudta (STE); utta (NAV); uta (AB); y el verbo 'hacer sombra' uta- (MON); otai (SC). Otros cognados o derivaciones con el sentido de "refugio», en pano, son péota 'tambo pequeño de unas pocas hojas de cañabrava' (de pei 'hoja' + ota 'sombra'), ota 'tambo pequeño' (LOR); hudtati 'lugar de descanso', pueota 'rancho' (STE); ota 'choza', 'casucha' (NAV); utaten 'lugar de descanso', pö-ôta 'sombra de hoja', 'rancho' (de pöi 'hoja') (AB); asimismo en SC, se reporta oti, otia 'tejer techo de palma muy tupido'.

En el caso del chipaya, aunque los datos son escasos, se puede establecer alguna que otra hipótesis preliminar. El único material consistente es aquel recopilado por el lingüista Cerrón-Palomino. Los términos para vivienda que se reporta en el diccionario chipaya son qhuya ${ }^{27}$ 'casa', putuku 'casa cónica', p'oqsa 'casa no cónica' y chhulli 'choza' (CER). Entre estos, el término putuku también es reportado en aimara de HUA y definido como 'casa antigua de adobe'. El término qhuya ${ }^{28}$ es similar al quechua koya 'ichu largo' (HOL); koya 'esparto largo' (TSC); koya 'espadaña (totora)' (ODT); q'oya 'esp. de paja' (MID). Las casas de los chipaya, qhuya, tienen paredes circulares hechas de adobe con techo de paja en forma de cúpula, mientras que el putuku es enteramente hecho de adobe en forma de cono ${ }^{29}$. En el mismo diccionario chipaya (CER) encontramos qhuya 'mata' y también en lengua aimara, formando parte de una raíz más larga, p. ej., sukuya 'ichu espinoso para cubrir las casas' (BER); sikuña 'estera' (MPF); sikuya 'esp. de hierba' (SE); sikuya 'paja, ichu' (HUA). Indudablemente el término chipaya fue prestado del quechua y aimara. El término putuku también parece ser préstamo del quechua y aimara bajo la forma de una raíz denotando una abertura o cavidad. Actualmente todavía podemos ver algunas formas que habrían sido parte del término original; por ejemplo, en lengua quechua tenemos pukru ‘hoyo' y hutqu 'agujero' (HOL); uchku 'hueco' (WE); p'ukru 'hoyo, cueva', hutqhu 'agujero' (TSC); puytoc, (h)uku, 'agujero', hutku 'perforar' (ODT); puitu 'sepulcro, cueva', p'ujru 'hoyo' (MID); uchku 'hueco, cueva' (TOD); pukru 'hoyo, cueva', uktu 'hueco', uku 'dentro', 'cuarto' (GR). En lengua aimara: phutunqu, phujru 'hoyo' (BER); phusa 'ahuecado' (MPF); phutunku 'hoyo' (SE); putu 'hueco, cueva', phujru 'hoyo' (HUA). Esto incita a pensar si el otro término, $p$ 'oqsa 'casa no cónica', no sería acaso un derivado de dos antiguas raíces: el primero siendo */pu-/ denotando un objeto o lugar

\footnotetext{
${ }^{27}$ En un artículo de Métraux $(1935,100)$, encontramos también $k^{x}$ oya /q q $^{\mathrm{h}}$ a/ 'casa' para el uro (chipaya) de Desaguadero.

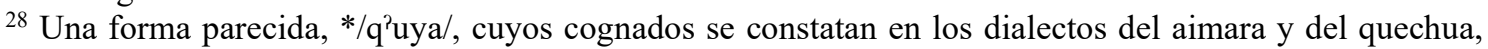
denota 'mina' o 'hueco'. Si bien está dentro de los posibles étimos, lo veo poco probable ante la evidencia de un significado ligado al ámbito vegetal.

${ }^{29}$ En Bastien (2012, 23-25), encontramos referencias a la vivienda chipaya, así también fotografías.
} 
ahuecado y */ukša/ ${ }^{30}$ denotando paja. Aunque el $p$ 'oqsa es hecho todo de adobe y es dudoso, por lo tanto, que tenga vínculo lexical con la paja. De esta hipotética raíz */pu-/ también se habría derivado el nombre chipaya pukara que es una especie de torre de piedra que servía para vigilar y defenderse de los enemigos; en BER encontramos alusiones a cueva, $p$. ej., sut'i pukara 'cueva de niguas', Iuntatanakana pukarapa 'cueva de ladrones'. La otra parte de palabra -kara es oscura, aunque tal vez es cognado con el aimara qala 'piedra' y el chipaya cara 'piedra calcárea'.

Un hecho interesante, respecto a los términos principales analizados en este artículo: wasi, uta y qhuya, es que las coberturas de las viviendas generan una concepción psicológica más profunda que otras partes de la construcción. El nombre del material del que está hecho el techo deriva muchas veces el nombre mismo de la casa.

\section{Resultados y conclusiones}

Se había planteado, en la sección 3.1, que wasi tiene relación con la antigua raíz amazónica */basi/ y que esta no se subsume al tronco quechua (aunque tampoco en sentido inverso). El término protopano */wasi/ adoptado del protoquechua indicaría la existencia del sonido semivocálico /w/ por lo menos alrededor del 2000 AP; por lo tanto, apelando al Cuadro 1, */basi/ sería netamente campa, mientras que */wasi/ sería del piro y del quechua. De hecho, el significado se mantiene estable, ya que */wasi/, o más bien */(a)wa-/, es bastante recurrente en lenguas amazónicas abarcando el campo semántico vegetal. Por ejemplo, en lengua yukuna ( $\mathrm{SCH}$ ), waji es una palmera cuyas hojas se utilizan para hacer los techos; en amarakaeri (TR), huãsĩ? es un árbol con hojas grandes (aunque no se especifica la utilidad de las hojas). En lengua uru, CréquiMontfort y Rivet $(1926,137)$ reportan huata 'casa' y huatha 'pueblo'. Por otro lado, la raíz */(a)wa/ está contenido en un sinnúmero de términos arawak denotando elementos vegetales; véase, por ejemplo, la lista reunida por Rivet y Wavrin $(1951,222)$ para el enunciado ÁRBOL. Ahora bien, veamos cómo sería la evolución del término en el siguiente cuadro.

Cuadro 3:

\begin{tabular}{|c|c|c|}
\hline \multirow{3}{*}{$\begin{array}{l}\text { pre-proto } \\
\text { */(a)wa-/ } \\
\text { 'hoja' } \\
\text { 'palmera' } \\
\text { 'bambú' } \\
\text {... }\end{array}$} & $\begin{array}{l}\text { protocampa } \\
\text { */basi/ 'hoja' }\end{array}$ & $\begin{array}{l}\text { campa } \\
\text { /basi/ 'hoja' } \\
\text { 'techar' }\end{array}$ \\
\hline & $\begin{array}{l}\text { protopiro } \\
\text { */wasi/ 'hoja' }\end{array}$ & $\begin{array}{l}\text { piro } \\
\text { /wasī/ 'hoja' } \\
\text { 'techar' }\end{array}$ \\
\hline & $\begin{array}{l}\text { protoquechua } \\
\text { */wasi/ 'techo, casa' }\end{array}$ & $\begin{array}{l}\text { quechua } \\
\text { /wasi/ 'casa' }\end{array}$ \\
\hline
\end{tabular}

\footnotetext{
${ }^{30}$ Encontramos cognados visibles en los dialectos quechuas: ocssa 'paja para cama' (STO); ogsha 'paja' (WE); oksa 'heno' (ODT); ujcha 'yerba', 'paja' (MID); uksha 'paja' (LAN); uksha 'paja' (GR).
} 
En suma, el término quechua wasi es un relicto de un preprotoquechua que interactuaba con los protoarawak subandinos. Los preprotoquechua ya ocupaban alguna zona específica de los Andes centrales, entre Junín, Pasco, Huánuco o Ancash, desde antes de los emplazamientos iniciales del Intermedio Temprano (200 a. C.-550 d. C.) (CERRÓN-PALOMINO, 2010). Es indudable la presencia cultural amazónica en su sociedad, facilitada por su ubicación en la cabecera de los ríos Marañón y Mantaro. Hornborg y Eriksen $(2011,139)$ postulan que en el Horizonte Temprano (900-200 a. C.) los arawak subandinos ya mantenían relaciones económicas y culturales con los pueblos andinos. En algún momento también mantuvieron relaciones con los pano antes de que se separase la rama nororiental mayoruna ${ }^{31}$, hace alrededor de 2000 años (FLECK, 2013, 21). La evidencia estaría en el nombre matsés uasin 'hierba', un probable préstamo (pre)protoquechua y que, como sabemos, la influencia inca-quechua no llegó hasta el este del actual departamento de Loreto que es la tierra de los matsés. La contradicción de esta hipótesis plantearía que el término fue llevado junto con el quechua misionero para la evangelización de la selva, sin embargo, ningún dialecto quechua conocido - desde la época colombina- emplea wasi para expresar paja, hierba o pasto.

Por lo tanto, la palabra */wasi/ 'hierba, paja' fue adoptada por el protopano antes de la división de los antiguos mayorunas alrededor del 2000 AP. Uno puede imaginar un escenario en el que los protopano, al ver a los protoquechuas tejer la paja sobre los techos, les preguntaron ¿qué material es eso? Los andinos creyeron que les preguntaban por el nombre de sus viviendas y ellos respondieron: */wasi/. Así, los protopano empezaron a llamar a la hierba o paja con este vocablo y se sumó a otros términos sinónimos que ya tenían. Para reforzar esta hipótesis, hay otro caso en el que los protopano ampliaron el significado de cierta palabra promovido por el contacto con los (proto)quechuas (tal vez en una época más reciente). El término para 'casa' en lenguas pano es */soßo/, cuyos cognados son shubu (FL); xobo (LO); shobo (LOR); sobo (STE); xubu (SH); $x o ́ b o(A B)$. En MON xubu se traduce como 'guarida, tambo'. El significado original de */soßo/ era alguna especie de palmera que actualmente se manifiesta en los nombres: shubu 'yarina, palmera usada para techar casas' (FL); xehpan 'irapai, palmera cuyas hojas se usan para techar' (LO); shebon 'palmera cuya hojas sirven para techar' (LOR); xöbõ 'uricuri, especie de palmera' (AB); xuvon 'shapaja' (palmera cuyas hojas sirven para techar) (HY). Todos estos, a excepción del último, son especies explícitamente utilizadas en el techado de las casas. Posteriormente, el término se modificó ligeramente con un nuevo significado al ver que los (proto)quechuas usaban la paja en vez de las hojas de palmera para techar, observe las derivaciones: xobi 'hierba bajera' (LO); shobi 'maleza, cizaña' (LOR); zubi 'hierba' (STE); xubi ‘hierba, pasto' (SH); xöbõ 'paja de maíz' ( $A B)$; xupo 'afrecho, bagazo' (HY).

En el caso del aimara, el hecho de que no se pueda rastrear la etimología a partir de un análisis intralingüístico sugiere también su

\footnotetext{
${ }^{31}$ La rama mayoruna comprende el matsés y el matis.
} 
antigüedad y su origen fuera de la familia lingüística. La adopción de uta en el aimara sureño no se debe a una adquisición reciente debido a que el término también existe en el aimara central, el jaqaru. Por lo tanto, */uta/ existe por lo menos desde antes de que se dividiera el preprotoamaira en la variedad central y sureña, el cual corresponde al periodo Intermedio Temprano (200 a. C.-550 d. C.) (CERRÓN-PALOMINO, $2010,262)$. El segmento */-ta-/ que comparten los tres troncos lingüísticos (arawak, pano y aimaraico) implica un contacto histórico en el tiempo que los antiguos arawak subandinos y los protopano mantenían una cercanía geográfica o compartían una zona franca. Se sabe que pueblos de lengua arawak llegaron del noreste del continente hacia el centro oriental del Perú, encontrándose con los pano del centro del Ucayali (HORNBORG; ERIKSEN, 2011, 133, 139; FLECK, 2013, 21). Cerca de allí, en la margen izquierda del Ucayali, emergió la subfamilia campa arawak. El encuentro e interacción entre las dos culturas amazónicas, arawak y pano, sucedió tan temprano desde por lo menos el Horizonte Temprano (1200-200 a. C.) (HORNBORG; ERIKSEN, 2011, 139) produciéndose, entonces, relaciones areales. Fleck (ibíd.), contradiciendo las estimaciones de Lathrap, conjetura que la dispersión inicial de los pano sucedió hace más de mil años, por lo menos alrededor de los 2000 años AP. En realidad, como muchos otros casos, se suscitaron idas y venidas, unas veces los pano consolidaban sus territorios y otras veces cedían ante los invasores arawak. Unos de estos periodos de dominio pano sucedió a mediados del primer milenio d. C. (HORNBORG; ERIKSEN, $2011,136)$ el cual coindice con la incursión de pueblos de lengua preprotoaimara de la costa central (Lima e Ica) hacia los Andes centrales (Ayacucho y Huancavelica) en el Intermedio Temprano (200 a. C.-550 d. C.) (CERRÓN-PALOMINO, 2010, 259).

A modo de resumen, no ha sido la intención de este artículo probar que las lenguas pre-protoquechua y el pre-protoaimara eran lenguas amazónicas. Más bien, lo que he propuesto es que los étimos de las palabras quechua y aimara que denotan «casa» son de estirpe amazónica, probablemente pre-protocampa. No se descarta que los pre-PQ y pre-PA hayan sido pueblos amazónicos, pero esta suposición traería más interrogantes por responder. En la otra línea de suposición, si estos protopueblos tomaron prestado la palabra de lenguas amazónicas, entonces habría que suponer que estos últimos eran más influyentes tecnológicamente que los pre-PQ y pre-PA. Sea como sea, la arqueología ha demostrado las relaciones interétnicas que se llevaban a cabo en zonas de tránsito interandinas y en el que los ancestros de los quechuas y aimaras formaron parte, mucho antes de que los imperios de los horizontes culturales impongan sus lenguas coloniales. Como manifiestan Hornborg y Eriksen $(2011,139)$, las intervenciones de los arawak del curso superior del Ucayali hizo posible un constante intercambio cultural y económico entre las tribus andinas y los protopano del curso inferior del Ucayali, llevado a cabo por lo menos desde el Horizonte Temprano (1200-200 a. C.). 


\section{Referencias bibliográficas}

ABREU, J. C. Rã-txa hu-ni-ku-ĩ: a lingua dos caxinauás do Rio Ibuaçu affluente do Muru. Rio de Janeiro: Typographia Leuzinger, 1914.

ADELAAR, W. F. H. Morfología del quechua de Pacaraos. Lima: Universidad Nacional Mayor de San Marcos, 1987.

ADELAAR, W. F. H. Trayectoria histórica de la familia lingüística quechua y sus relaciones con la familia lingüística aimara. Boletín de Arqueología, PUCP, nro. 14, pp. 239-254, 2010.

ALDERETES, J. R. El quichua de Santiago del Estero. Gramática y vocabulario. Tucumán: Facultad de Filosofía y Letras, Universidad Nacional de Tucumán, 2001.

ALLIN, T. Vocabulario resígaro. Lima: Instituto Lingüístico de Verano, 1979.

BASTIEN, J. W. People of the Water: Change and Continuity among the Uru-Chipayans of Bolivia. Salt Lake City: University of Utah Press, 2012.

BERTONIO, L. Vocabulario de la lengua aymara. Leipzig: B. G. Teubner, 1879 [1612].

BLACK, N. Lecciones para el aprendizaje del quechua del sureste de Pasco y el norte de Junín. Lima: Dirección Departamental de Educación-Pasco / Instituto Lingüístico de Verano, 1990.

BUCK, C. D. A Dictionary of Selected Synonyms in the Principal Indo-European Languages. Chicago: University of Chicago Press, 1988.

BURROW, T.; EMENEAU, M. B. A Dravidian Etymological Dictionary. 2nd ed. Oxford: Clarendon Press, 1984.

CERRÓN-PALOMINO, R. Contactos y desplazamientos lingüísticos en los Andes centro-sureños: el puquina, el aimara y el quechua. Boletín de Arqueología, PUCP, nro. 14, pp. 255-282, 2010.

CERRÓN-PALOMINO, R.; BALLÓN, E. Chipaya: Léxico - Etnotaxonomía. Lima: Fondo Editorial PUCP, 2011.

COBO, B. Historia del Nuevo Mundo. Sevilla: E. Rasco, 1893. Tomo IV.

CRÉQUI-MONTFORT, G.; RIVET, P. La langue Uru ou Pukina. Journal de la Société des Américanistes, vol. 18, pp. 111-139, 1926.

DE VAAN, M. Etymological Dictionary of Latin and the other Italic Languages. Leiden: Brill, 2008. 
Espaço Ameríndio

DUFF-TRIPP, M. Gramática del idioma yanesha' (amuesha). Lima: Instituto Lingüístico de Verano, 1997.

Verano, 1998.

Diccionario yanesha' (amuesha)-castellano. Lima: Instituto Lingüístico de

ERDMANN, F. Eskimoisches Wörterbuch gesammelt von den Missionaren in Labrador. Bautzen: Ernst Moritz Monse, 1864.

FLECK, D. W. Panoan Languages and Linguistics. Nueva York: American Museum of Natural History, 2013.

FLECK, D. W.; UAQUÍ, F.; JIMÉNEZ, D. Diccionario matsés-castellano. Iquitos: Tierra Nueva, 2012.

GRIMM, J. La lengua quichua (dialecto de la República del Ecuador). Friburgo de Brisgovia: B. Herder, 1897.

GONZÁLEZ HOLGUíN, D. Vocabulario de la lengua general del Perú llamada qquichua o lengua del Inca. Lima: Francisco del Canto, 1608.

HORNBORG, A.; ERIKSEN, L. An Attempt to Understand Panoan Ethnogenesis in Relation to Long-Term Patterns and Transformations of Regional Interaction in Western Amazonia. In: HORNBORG, A.; HILL, J. D. (eds.). Ethnicity in Ancient Amazonia. Boulder: University Press of Colorado, 2011. pp. 129-151.

HORNBORG, A.; HILL, J. D. Ethnicity in Ancient Amazonia. Boulder: University Press of Colorado, 2011.

HUAYHUA PARI, F. Diccionario bilingüe polilectal: aimara-castellano, castellanoaimara. Lima: Fondo Editorial UNMSM, 2009.

HYDE, S. Diccionario amahuaca. Yarinacocha: Instituto Lingüístico de Verano, 1980.

ITIER, C. Viracocha o el océano: naturaleza y funciones de una divinidad inca. Lima: Instituto Francés de Estudios Andinos / Instituto de Estudios Peruanos, 2013.

JIMÉNEZ DE LA ESPADA, M. Relaciones geográficas de Indias, Perú. Madrid: Tipografía de Manuel G. Hernández, 1885. Tomo II.

KEOKE, E. D.; PORTERFIELD, K. M. Trade, Transportation, and Warfare. New York: Facts On File, Inc, 2005.

KINDBERG, L. Diccionario asháninca. Yarinacocha: Instituto Lingüístico de Verano, 1980.

KLEIN, E. A Comprehensive Etymological Dictionary of the Hebrew Language for Readers of English. Jerusalem: Carta / The University of Haifa, 1987. 
Espaço Ameríndio

LANDERMAN, P. Vocabulario quechua del Pastaza. Yarinacocha: Instituto Lingüístico de Verano, 1973.

LAVAllÉE, D. The First South Americans: The Peopling of a Continent from the Earliest Evidence to High Culture. Salt Lake City: University of Utah Press, 2000.

LOOS, E.; LOOS, B. Diccionario capanahua-castellano. Lima: Instituto Lingüístico de Verano, 1998.

LORIOT, J.; LAURIAULT, E.; DAY, D. Diccionario shipibo-castellano. Lima: Instituto Lingüístico de Verano, 1993.

MANDRINI, R. América aborigen. De los primeros pobladores a la invasión europea. Buenos Aires: Siglo Veintiuno, 2013.

MARKHAM, C. R. Contributions towards a Grammar and Dictionary of Quichua. Londres: Trübner \& Co, 1864.

MÉNDEZ, C. Los primeros andinos. Tecnología lítica de los habitantes de Chile trece mil años atrás. Lima: Fondo Editorial PUCP, 2015.

MÉTRAUX, A. Contribution à l'ethnographie et à la linguistique des Indiens Uro d'Ancoaqui (Bolivie). Journal de la Société des Américanistes, vol. 27, nro. 1, pp. 75$110,1935$.

MIDDENDORF, E. W. Wörterbuch des Runa Simi oder der Keshua-Sprache. Leipzig: F. A. Brockhaus, 1890.

MIHAS, E. Essentials of Ashéninka Perené Grammar. 2010. 335 pp. Thesis (PhD). Milwaukee: University of Wisconsin-Milwaukee, 2010.

MISIONEROS de los Colegios de Propaganda Fide del Perú. Vocabulario castellanoaymara. Lima: Imprenta del Colegio de Propaganda Fide del Perú, 1905.

MONTAG, S. Diccionario cashinahua. Yarinacocha: Instituto Lingüístico de Verano, 1981.

MOORE, J. D. The Prehistory of Home. Berkeley: University of California Press, 2012.

MORALES CHOCANO, D. Aportes amazónicos al formativo andino. Investigaciones Sociales, año 5, nro. 8, pp. 35-64, 2001.

MUÑOZ MORÁN, O. Cueva, piedra y adobe. La comprensión quechua del cambio social por medio de la casa. Revista Española de Antropología Americana, vol. 42, nro. 2, pp. 515-532, 2012.

NASH, D. J. Household Archaeology in the Andes. Journal of Archaeological Research, no. 17, pp. 205-261, 2009. 
Espaço Ameríndio

NAVARRO, M. Vocabulario castellano-quechua-pano con sus respectivas gramáticas quechua y pana. Lima: Imprenta del Estado, 1903.

NIES, J. Diccionario piro (yine). Lima: Instituto Lingüístico de Verano, 1986.

OLIVEIRA, S. C. S. Contribuições para a reconstrução do protopáno. 2014. 492 f. Tese (Doutor em Linguística). Brasília: Universidade de Brasília, 2014.

ONFFROY DE THORON, E. Grammaire et Dictionnaire Français - Kichua. Paris: Ernest Leroux, 1886.

OREL, V. E.; STOLBOVA, O. V. Hamito-Semitic Etymological Dictionary: Materials for a Reconstruction. Leiden: Brill, 1995.

ORR, C.; WRISLEY, B. Vocabulario quichua del Oriente. 2. ${ }^{a}$ ed. Quito: Instituto Lingüístico de Verano, 1981.

PAYNE, D. Diccionario ashéninca-castellano. Lima: Instituto Lingüístico de Verano, 1980.

PRICE, T. D.; BROWN, J. A. Prehistoric Hunters-Gatherers: The Emergence of Cultural Complexity. Orlando: Academic Press, 1985.

RADEMAKER, K. et al. Paleoindian Settlement of the High-Altitude Peruvian Andes. Science, vol. 346, nro. 6208, pp. 466-469, 2014.

RIVET, P.; WAVRIN, R. Un nouveau dialecte arawak: le Resígaro. Journal de la Société des Américanistes, vol. 40, pp. 203-239, 1951.

ROJAS-BERSCIA, L. M.; GHAVAMI-DICKER, S. Teonimia en el alto Amazonas. El caso de Kanpunama'. Escritura y Pensamiento, UNMSM, año 18, nro. 36, pp. 117-146, 2015.

RUBIO, D. T.; FIGUEREDO, J. Arte y vocabulario de la lengua quichua general de los indios del Perú. Lima: Imprenta de la Plazuela de San Cristobal, 1754 [1619].

SAEGERT, S. The Role of Housing in the Experience of Dwelling. In: ALTMAN, I.; WERNER, C. M. (eds.). Home Environments. Nueva York: Plenum Press, 1985. pp. 287-309.

SANTO TOMÁS, D. Lexicon, o Vocabulario de la lengua general del Peru. Valladolid: Francisco Fernandez de Cordoua, 1560.

SCARRE, C. The Human Past: World Prehistory \& the Development of Human Societies. 3rd ed. Nueva York: Thames \& Hudson, 2013.

SCHAUER, S. et al. Diccionario bilingüe: yukuna-español, español-yukuna. Bogotá: Editorial Fundación para el Desarrollo de los Pueblos Marginados, 2005. 
Espaço Ameríndio

SCHUESSLER, A. ABC Etymological Dictionary of Old Chinese. Honolulu: University of Hawai'i Press, 2007.

SCOTT, M. Vocabulario sharanahua-castellano. Lima: Instituto Lingüístico de Verano, 2004.

SEBEOK, T. A. Materials for an Aymara Dictionary. Journal de la Société des Américanistes, vol. 40, pp. 89-151, 1951.

SEILER, W. A. Iñupiatun Eskimo Dictionary. Dallas: SIL International, 2012.

SHAVER, H. Diccionario nomatsiguenga-castellano, castellano-nomatsiguenga. Yarinacocha: Instituto Lingüístico de Verano, 1996.

SHELL, O. Vocabulario cashibo-cacataibo. Lima: Instituto Lingüístico de Verano, 1987.

SMITH, R. CH. ¿Un sustrato arawak en los Andes centrales? La historia oral y el espacio histórico cultural yánesha. In: CHAUMEIL, J.-P.; ESPINOSA DE RIVERO, O.; CORNEJO, M. (eds.). Por donde hay soplo. Lima: Instituto Francés de Estudios Andinos / PUCP / CAAAP, 2011. pp. 219-254.

SNELL, B. A. Diccionario matsigenka - castellano. Lima: Instituto Lingüístico de Verano, 2011.

SOPENA. Diccionario enciclopédico ilustrado Sopena. Barcelona: Editorial Ramón Sopena, 1981. Tomo 1.

TÖDTER, C.; WATERS, W.; ZAHN, C. Diccionario inga-castellano (quechua del Pastaza). Lima: Instituto Lingüístico de Verano, 2002.

TORERO, A. Los dialectos quechuas. Fabla, año 2, nro. 2, pp. 11-61, 2003.

TRIPP, R. Diccionario amarakaeri-castellano. Yarinacocha: Instituto Lingüístico de Verano, 1995.

VARGAS NALVARTE, P. C. Huacas limeñas: ancestros amazónicos. Arqueología y Sociedad, UNMSM, nro. 31, pp. 327-340, 2016.

VON DEN STEINEN, K. Diccionario sipibo. Castellano-deutsch-sipibo. Berlin: Dietrich Reiner, 1904.

VON TSCHUDI, J. J. Die Kechua-Sprache: Wörterbuch. Wien: Kaiserlich-Königlichen Hof- und Staatsdruckerei, 1853.

WEBER, D. J. et al. Rimaycuna: Quechua de Huánuco. Lima: Instituto Lingüístico de Verano, 1998.

WILKINSON, D. The influence of Amazonia on state formation in the ancient Andes. Antiquity, vol. 92, no. 365, pp. 1362-1376, 2018. 
ZARIQUIEY, R. Vocabulario iskonawa-castellano-inglés. Medford: Department of Romance Languages, Tufts University, 2016.

\section{Abreviaturas de diccionarios}

AB cashinahua, Abreu, 1914

ADE quechua de Pacaraos, Adelaar, 1987

AL resígaro, Allin, 1979

ALD quechua, Alderetes, 2001

BER aimara, Bertonio, 1879

BL quechua de Pasco y Junín, Black, 1990

CER chipaya, Cerrón-Palomino y Ballón, 2011

DUF yanesha, Duff-Tripp, 1998

FL matsés, Fleck et al., 2012

GR quechua, Grimm, 1897

HOL quechua, González Holguín, 1608

HUA aimara, Huayhua, 2009

HY amahuaca, Hyde, 1980

KIN asháninka, Kindberg, 1980

LAN quechua, Landerman, 1973

LO capanahua, Loos y Loos 1998

LOR shipibo, Loriot et al., 1993

MAR quechua, Markham, 1864

MID quechua, Middendorf, 1890

MON cashinahua, Montag, 1981

MPF aimara, Misioneros, 1905

NAV pano, Navarro, 1903

NI piro (yine), Nies, 1986

ODT quechua, Onffroy de Thoron, 1886

O\&W quechua, Orr y Wrisley, 1981

PA ashéninka, Payne, 1980

RU quechua, Rubio y Figueredo, 1754

SC sharanahua, Scott, 2004

SCH yukuna, Schauer, 2005

SE aimara, Sebeok, 1951

SH cashibo-cacataibo, Shell, 1987

SHA nomatsiguenga, Shaver, 1996

SN matsigenka, Snell, 2011

STE shipibo, von den Steinen, 1904

STO quechua, Santo Tomás, 1560

TOD quechua, Todter et al., 2002

TR amarakaeri, Tripp, 1995

TSC quechua, von Tschudi, 1853

WE quechua, Weber et al., 1998

ZAR iskonawa, Zariquiey, 2016 
Recebido em: 14/12/2018 * Aprovado em: 04/08/2019 * Publicado em: 30/12/2019 